ARTIGOS

\title{
PROGRAMA DE RESIDÊNCIA PEDAGÓGICA: CONEXÕES ENTRE A FORMAÇÃO DOCENTE E A EDUCAÇÃO BÁSICA
}

\author{
Alba Regina Battisti de SOUZA \\ Universidade do Estado de Santa Catarina - UDESC \\ Florianópolis, Santa Catarina-Brasil \\ alba.faed@gmail.com \\ https://orcid.org/0000-0002-1361-2626 \\ Lourival José MARTINS FILHO \\ Universidade do Estado de Santa Catarina - UDESC \\ Florianópolis, Santa Catarina-Brasil \\ lourivalfaed@gmail.com \\ http://orcid.org/0000-0002-8464-7236 \\ Rosa Elisabete Militz Wypyczynski MARTINS \\ Universidade do Estado de Santa Catarina - UDESC \\ Florianópolis, Santa Catarina-Brasil \\ rosamilitzgeo@gmail.com \\ https://orcid.org/0000-0002-2875-2883
}

RESUMO: O artigo tem como objetivo problematizar e analisar as possíveis conexões promovidas pelo Programa de Residência Pedagógica (PRP) com a Educação Básica, considerando a formação inicial, a relação entre as instituições formadoras e a inserção dos licenciandos nas escolas. Como objeto de estudo, foram consideradas as experiências dos próprios autores, participantes do programa e docentes dos cursos de Geografia e de Pedagogia de uma instituição pública estadual de ensino superior. Documentos oficiais, institucionais e relatórios constituem os dados coletados. Os resultados do estudo demonstram que o PRP intensificou as relações com as escolas e a participação das professoras preceptoras possibilitou aos residentes uma contínua e ampliada convivência com o contexto escolar, aprimorando o processo formativo e fomentando a relação teoria e prática. O trabalho desencadeou uma série de problematizações quanto ao formato e abrangência do programa como uma política de formação docente.

PALAVRAS-CHAVE: Formação Docente. Programa de Residência Pedagógica. Relação Universidade e Escola. 


\title{
PEDAGOGICAL RESIDENCE PROGRAM: CONNECTIONS BETWEEN TEACHING TRAINING AND BASIC EDUCATION
}

\begin{abstract}
The article aims to problematize and analyze possible connections promoted by the Pedagogical Residency Program (PRP) with Basic Education, considering this initial education as well as the relationship between training institutions and the insertion of training teachers in schools. As object of study, the experiences of the authors themselves, participants of the program and teachers of the Geography and Pedagogy courses of a public state institution of higher education were considered. Official, institutional documents and reports constitute the collected data. The results of the study demonstrate that the PRP has intensified relations with schools and the participation of tutors has enabled residents to have a continuous and expanded coexistence within the school context, improving the training process and fostering the relationship between theory and practice. The work triggered a series of questioning regarding the format and scope of the program as a teacher training policy.
\end{abstract}

KEYWORDS: Teacher Training. Pedagogical Residency Program. University-School Relationship.

RESUMEN: El artículo tiene como objetivo problematizar y analizar las posibles conexiones que promueve el Programa de Residencia Pedagógica (PRP) con la Educación Básica, considerando la formación inicial, la relación entre las instituciones de formación y la inserción de los estudiantes de pregrado en las escuelas. Como objeto de estudio se consideraron las experiencias de los propios autores, participantes del programa y docentes de los cursos de Geografía y Pedagogía de una institución pública estatal de educación superior. Los documentos e informes oficiales e institucionales constituyen los datos recopilados. Los resultados del estudio demuestran que el PRP ha intensificado las relaciones con las escuelas y la participación de los profesores tutores ha permitido que los residentes tengan una convivencia continua y ampliada con el contexto escolar, mejorando el proceso de formación y fomentando la relación entre teoría y práctica. El trabajo desencadenó una serie de problemas en cuanto al formato y alcance del programa como política de formación docente.

PALABRAS CLAVE: Formación del profesorado. Programa de Residencia Pedagógica. Relación Universidad y Escuela. 


\section{Introdução}

O artigo apresenta resultados de um estudo sobre o Programa de Residência Pedagógica (PRP) - Edital CAPES n $n^{\circ}$ 06/2018 (CAPES, 2018), tomando como objeto o projeto institucional e os subprojetos de dois cursos de Licenciatura - Pedagogia e Geografia -, de uma universidade pública estadual. As seguintes problematizações mobilizaram e permearam o trabalho: O PRP pode realmente propiciar uma relação mais próxima com as escolas e professores/as da Educação Básica, com vistas a parcerias e ações conjuntas na formação docente? O PRP pode desencadear uma formação inicial mais contextualizada e articulada teórica e metodologicamente quanto ao campo de atuação dos futuros/as professores/as? Quais as possíveis implicações do PRP frente às políticas públicas para a educação, suas possibilidades e contradições?

Nos estudos sobre a formação docente na atualidade são correntes as produções e discussões voltadas para a defesa de uma formação inicial mais articulada com a Educação Básica. Nóvoa (2017) defende uma formação híbrida, como forma de ligação e mobilidade, uma espécie de "entre-lugar", entre universidades, escolas e políticas públicas, e incluindo, para isso, um estatuto de formador para ambos: professores universitários e professores da Educação Básica.

Tardif (2002), ao apresentar um panorama de movimentos reformistas educacionais, ocorridos nos anos 1990, destaca alguns objetivos, dentre os quais:

Estabelecer uma ligação entre as instituições universitárias de formação de professores e escolas. [...] As escolas tornam-se, assim, lugares de formação, de inovação, de experimentação e de desenvolvimento profissional, mas também, idealmente, lugares de pesquisa e de reflexão crítica. (TARDIF, 2002, p. 280).

No Brasil, há algum tempo, estudos sobre a relação da universidade com as escolas fazem parte das discussões. A esse respeito podemos citar o trabalho de Lüdke e Cruz (2005) no qual é abordada a pesquisa na Educação Básica e na formação inicial, e são tecidas importantes reflexões voltadas para nossa realidade. Segundo as autoras:

Nossos cursos de formação de professores têm sofrido as consequências de um defeito congênito de sua constituição: a separação entre teoria e prática no esforço de formação, colocando, em geral, em posição precedente a teoria, vindo a prática sempre depois, por meio de estágios de duração insuficiente e, sobretudo, de concepção precária. (LÜDKE; CRUZ, 2005, p. 85).

Em se tratando do Plano Nacional de Educação (PNE), na meta 15, sobre a Política Nacional de Formação de Profissionais da Educação, há menção da estratégia de articulação entre a formação acadêmica e as demandas da Educação Básica e prevê: " [...] a ampliação de programa permanente de iniciação à docência a estudantes matriculados em cursos de licenciatura, a fim de incentivar a formação de profissionais do magistério para atuar na Educação Básica pública." (BRASIL, 2014, p. 49).

São discursos aparentemente uníssonos, tanto por parte de pesquisadores e docente atuantes nas instituições formadoras como parte dos argumentos das propostas presentes em políticas de formação para Educação Básica, como o PRP, porém, com matizes, pressupostos e ações que os diferem. Assim, é importante demarcar, como professores e pesquisadores do campo da educação, em especial da formação de professores, que nossa decisão quanto à participação no PRP foi acompanhada de uma postura crítica, 
criativa e investigativa, não apenas no sentido de realizar os subprojetos e planos de trabalho previstos, mas também de problematizar, analisar e estudar a proposta. Além disso, essa postura não é uma exclusividade frente ao PRP, mas também a edições do Programa Institucional de Bolsa de Iniciação à Docência (PIBID) e sobre nossos projetos e ações enquanto professores e pesquisadores atuantes na área de estágios curriculares, planejamento e avaliação, tanto na graduação como em programa de pós-graduação em Educação.

Conforme prevê o Edital Capes nº 06/2018, o Programa Residência Pedagógica é uma das ações que integram a Política Nacional de Formação de Professores e visa:

1. Aperfeiçoar a formação dos discentes de cursos de licenciatura, por meio do desenvolvimento de projetos que fortaleçam o campo da prática e conduzam o licenciando a exercitar de forma ativa a relação entre teoria e prática profissional docente, utilizando coleta de dados e diagnóstico sobre o ensino e a aprendizagem escolar, entre outras didáticas e metodologias;

II. Induzir a reformulação do estágio supervisionado nos cursos de licenciatura, tendo por base a experiência da residência pedagógica;

III. Fortalecer, ampliar e consolidar a relação entre a IES e a escola, promovendo sinergia entre a entidade que forma e a que recebe o egresso da licenciatura e estimulando o protagonismo das redes de ensino na formação de professores.

IV. Promover a adequação dos currículos e propostas pedagógicas dos cursos de formação inicial de professores da Educação Básica às orientações da Base Nacional Comum Curricular (BNCC). (CAPES, 2018, p. 1).

O referido Edital define o PRP como " [...] uma atividade de formação realizada por um discente regularmente matriculado em curso de licenciatura e desenvolvida numa escola pública de Educação Básica, denominada escola-campo." (CAPES, 2018, p. 1). Além disso, detalha as principais atividades e respectiva carga horária, a saber: duração total de 440 horas, divididas em 60 horas para ambientação na escola, 320 horas para imersão (das quais 100 horas devem ser de regência - planejamento e práticas docentes), e 60 horas para a elaboração de relatório final, avaliações e socializações. Ainda de acordo com o Edital, com relação aos participantes e suas denominações, os discentes licenciandos são denominados residentes, ao passo que os professores das IES, responsáveis pela orientação, são denominados docentes orientadores; nas escolas-campo, os/as professores/as responsáveis pelo acompanhamento dos/as residentes são denominados/as preceptores/as; por fim, a coordenação institucional é exercida por um/a docente da IES.

A Universidade em questão, como uma instituição pública, assume o compromisso de contribuir para a Política Nacional de qualificação e aprimoramento da Educação Brasileira. Nesse sentido, o PRP configurou-se como mais uma oportunidade por meio de ações de ensino, estágios, pesquisa e extensão, de manter um diálogo permanente com a Educação Básica, a fim de contribuir para a formação inicial dos licenciandos bem como para os contextos educativos e curriculares onde nos encontramos.

Dentro desse posicionamento, destacamos que a imersão dos/as licenciandos/as nas escolas de Educação Básica, via o PRP, segue uma parceria entre professores/as da Universidade, professores/as da escola e os/ as próprios/as licenciandos/as, numa perspectiva dialógica e participativa, na feitura de uma escola realmente solidária e inclusiva e indo ao encontro de premissas construídas ao longo de nossa trajetória e experiência na formação de professores, no âmbito do ensino, pesquisa e extensão. 
Então, a fim de contribuir para a formação crítica dos/as licenciandos/as em Geografia e Pedagogia, foi reconhecido o alcance previsto no projeto institucional do PRP (UDESC, 2018): contribuir no repensar dos estágios, práticas curriculares e formas de inserção nos contextos escolares; identificar demandas de formação continuada nos contextos escolares, realizando de forma colaborativa e integrada momentos de reflexão entre Universidade e escolas de Educação Básica; qualificar o percurso curricular com ênfase nos estágios dos cursos de Geografia e Pedagogia.

\section{Aportes teóricos e metodológicos do PRP/UDESC}

Em relação à ação docente no Programa Residência Pedagógica (PRP) partimos da compreensão de que o trabalho intencional do professor na Educação Básica e no ensino superior precisa possibilitar aos estudantes uma gama de saberes fundamentais para a vida e o mundo com todos os seus desafios. Compreendemos que este seja um importante passo para a construção de uma ação docente que concretize a escola como lugar privilegiado para se viver cada categoria geracional numa perspectiva mais humana, laica e inclusiva. Num diálogo com A. Martins Filho e L. Martins Filho (2012) compreendemos a escola como um lugar onde os diferentes sujeitos possam falar, ouvir, ver, sentir, ensinar, aprender, pensar, resistir, concordar, discordar, escrever, ler, ou seja, onde podem tecer suas histórias e se perceberem como produtores de culturas e transformadores da sociedade.

Dessa forma, podemos afirmar, sob a perspectiva de autores como Vygotsky (1982) em suas análises sobre a natureza do trabalho educacional, que é pela apropriação da experiência humana que o homem se constitui como ser humano. Sob essa ótica, a educação escolar pode ser considerada a atividade, por excelência, do processo de constituição de humanização do próprio ser humano.

Nesse sentido, o Programa Residência Pedagógica assumiu uma concepção de aprendizagem em que a cultura e a formação humana ocorrem desde o nascimento e precisam ser mediadas e qualificadas por parceiros mais experientes e com formação para travar relações intencionalmente mediadas nos contextos escolares. Assim, há sem dúvida uma necessidade de pensarmos os processos educativos como atividade social mediadora qualificando o trabalho docente, e esse profissional terá como função selecionar, organizar, sistematizar e planejar os conteúdos a serem explorados nos ambientes escolares.

Nossa pretensão é, portanto, anunciar a formação intelectual como marca essencial da docência. Para A. Martins Filho e L. Martins Filho (2012) isso passa a ser possível quando o professor participa de processos de formação que o humanizam, o intelectualizam e ampliam sua formação cultural.

Na perspectiva da pesquisa-ação, o Programa Residência Pedagógica em questão pautou-se na vivência de situações concretas e compartilhadas em função da identificação e compreensão de problemas detectados no contexto da docência. Numa abordagem qualitativa, o programa não assumiu uma posição de neutralidade científica frente aos contextos escolares.

Consideramos que um dos desafios dos cursos de licenciatura é garantir a realização de práticas pedagógicas e curriculares realmente geradoras de aprendizagem. Optamos, então, pela pesquisa-ação, pois esta, conforme Thiollent (2005), é um tipo de pesquisa social com base empírica que é concebida e realizada em estreita associação com uma ação ou com a resolução de um problema coletivo e no qual os pesquisadores e os participantes representativos da situação ou do problema estão envolvidos de modo cooperativo ou participativo. Ainda num diálogo com o referido autor, tínhamos sempre em mente que na pesquisa-ação um 
dos principais objetivos consiste em construir em conjunto com os pesquisadores e grupos de participantes os meios de se tornarem capazes de interpretar e lidar com problemas da situação em que vivem.

Assim, também integramos teórica e metodologicamente a pesquisa-ação educacional, a partir de Tripp (2005), como um tipo de investigação-ação caracterizado pelo aprimoramento da prática pelo sistemático processo entre o agir no campo da prática e o investigar sobre ela. De acordo com o autor: "Planeja-se, implementa-se, descreve-se e avalia-se uma mudança para a melhora de sua prática, aprendendo mais, no correr do processo, tanto a respeito da prática quanto da própria investigação." (TRIPP, 2005, p. 446). Portanto, trata-se de uma imersão na práxis do grupo social tal como define Franco (2005).

Outro princípio que o PRP buscou reafirmar trata da inter-relação formativa e colaborativa com a Educação Básica. As escolas parceiras representam mais que um papel de concessão de programas ou projetos, uma dimensão essencial no processo formativo dos licenciandos. Seguimos a ideia de Nóvoa (2009, p. 214) sobre a escola "[...] como o lugar da formação dos professores, como o espaço da análise partilhada das práticas, enquanto rotina sistemática de acompanhamento, de supervisão e de reflexão sobre o trabalho docente." Nesse sentido, também buscamos na pesquisa colaborativa elementos para sustentar as ações coformativas, a partir da definição propostas por Desgagné, (2007, p. 7):

1) a abordagem colaborativa supõe um processo de co-construção entre os parceiros envolvidos; 2) joga simultaneamente sobre dois registros, que é o da produção de conhecimentos e o do desenvolvimento profissional dos docentes; 3) contribui para a aproximação e mediação entre comunidade de pesquisa e escolar.

O PRP/UDESC organizou as 440 horas de estágio por meio das seguintes etapas articuladas: a) formação e orientação inicial na Universidade; b) período de inserção na escola-campo; c) período de ambientação na escola-campo; d) período de imersão na escola-campo; e) período de planejamento e replanejamento na escola-campo e na Universidade; f) período de prática docente na escola-campo; g) período de sistematização contínua e final das experiências; h) socializações intermediárias e socialização geral na escola-campo e na Universidade, abertas ao público.

Permeando as etapas citadas ocorreram as formações contínuas, produções de materiais e recursos didáticos, participação em eventos, orientações individuais e grupais, reuniões diversas, avaliações paralelas e registros por meio de diários e outros recursos. Esse conjunto de atividades constituíram um movimento articulado entre os conhecimentos teórico-metodológicos inerentes ao processo formativo e às experiências elaboradas nas escolas-campo. Assim, a relação teoria e prática se constituiu como um dos cernes do PRP e, por conseguinte, dinâmica, complexa e muitas vezes contraditória e conflituosa, o que, no nosso entendimento, é inerente ao caráter dialético e crítico da formação docente.

\section{O Programa de Residência Pedagógica do curso de Pedagogia}

O PRP do curso de Pedagogia foi realizado em três escolas parceiras da Rede Pública de Ensino - uma estadual e duas municipais - e institucionalmente vinculado aos estudos sobre as políticas educacionais do Grupo de Pesquisa Didática e Formação Docente (Nape) e ao Programa de Extensão Olhares.

As professoras preceptoras, efetivas das respectivas redes de ensino e com significativa experiência em docência, participaram ativamente do programa em todas as etapas, tanto na escola-campo, com acompanhamento, direcionamento de atividades, orientações e avaliações contínuas, como na Universidade, em 
reuniões de avaliação, participação em eventos, nas formações e orientações coletivas. Assim, conseguimos realizar de forma dialogada e compartilhada o que preconiza Nóvoa (2019, p. 17) quanto a permeabilidade e imbricação entre a "comunidade dos formadores de professores" e a "comunidade dos professores".

As atividades dos residentes de Pedagogia Anos Iniciais foram precedidas por uma formação na qual foram esclarecidos os objetivos do Programa, suas premissas, etapas e processos. Também foram apresentados e discutidos roteiros de observação e participação e as diversas formas de registro. Os residentes participaram de reuniões semanais e/ou quinzenais na Universidade para estudos, orientações e avaliações sob a coordenação da orientadora e, em diversas ocasiões, com a participação das preceptoras.

As atividades dos residentes nas escolas-campo ocorreram prevendo uma gradativa inserção, imersão e autonomia, como: reconhecimento e familiarização com o contexto escolar; vivências nos diversos espaços e atividades da escola-campo; observações e interações em sala de aula dos anos iniciais; compreensão dos processos pedagógicos e de gestão e estudo dos documentos, como o Projeto Político-Pedagógico (PPP) das escolas; reconhecimento da estrutura e composição curricular dos anos iniciais, dos planos de ensino e dos processos de condução e mediação pedagógica em sala de aula; organização de proposta docente (projeto de docência) e planos de aula; prática docente (regência); relatório final. Os residentes realizaram registros contínuos em diários de campo e fotográficos, que serviram de base para os relatórios parciais e final.

As avaliações das atividades e do desempenho dos residentes foram acompanhadas pelas preceptoras e pela orientadora a fim de subsidiarem os momentos de orientação e o redimensionamento contínuo. De forma coletiva, individual e autoavaliativa, consideraram, de forma geral: desempenho e compromisso na interação com as crianças e professora preceptora; atividades em sala de aula; interesse e participação nas atividades desenvolvidas na escola e nas reuniões de estudo e orientações; organização e apresentação dos materiais de registros, postura ética, assiduidade, pontualidade, organização do projeto de docência e planos de aula, desempenho na prática docente (regência), preparo dos materiais de síntese e socialização.

Por termos dentre os princípios de formação a socialização, a formação contínua e construção de parcerias, também foram estimuladas e viabilizadas a participação dos residentes de Pedagogia em seminários, reuniões e eventos da área da Educação para socializar as experiências vivenciadas no cotidiano das escolas onde os projetos foram desenvolvidos. Além disso, em diversos momentos, os licenciandos puderam compartilhar algumas dessas atividades com os/as residentes de Geografia.

As ações docentes do PRP/Pedagogia foram organizadas por meio de projetos de docência. A partir de temas oriundos do contexto da escola e da sala de aula, e com base nos conteúdos escolares os/as residentes organizaram os planos de aula com problematizações e atividades mobilizadoras. Os projetos de docência possibilitam que os componentes curriculares tomassem forma e sentido seguindo uma dinâmica mais aberta e integrada, primando por um processo ensino-aprendizagem mais contextualizado e participativo, sem minimizar ou deixar de lado os componentes e conteúdos curriculares.

Quanto aos resultados do PRP/Pedagogia, tomamos como base depoimentos do relatório final dos residentes (UDESC, 2019), nos quais pudemos perceber o impacto de uma inserção expandida e coformativa nas escolas. Dentre tais depoimentos, destacamos: contribuição para a formação nos aspectos teóricos e práticos; significativo aumento da confiança para atuar na educação dos anos iniciais; possibilidade de acionar aspectos teóricos da formação durante o processo de observações e participação na escola; experiência mais abrangente e ampla que os estágios curriculares obrigatórios da Pedagogia; imersão na sala de aula e na 
profissão docente; orientação e acompanhamento contínuo contribuindo para o aprimoramento em todas as etapas; sentimento de segurança e amparo pela presença e acompanhamento das professoras preceptoras; exercício do planejar as aulas e se preparar para as situações inesperadas que ocorrem na ação docente; como organizar e conduzir as atividades; possibilidade de conhecer as crianças e suas particularidades; reconhecimento da importância da pesquisa e aperfeiçoamento contínuo para a docência.

Também foi possível identificar, por parte das preceptoras, manifestações positivas com a experiência de atuarem no PRP, em especial por se sentirem partícipes da formação, pela ênfase ao trabalho conjunto entre Universidade e escola, como as reuniões e momentos de formação na IES, e pelo acompanhamento da professora orientadora da IES na escola. E tal como consta nos documentos de acompanhamento: "Em resumo, era a universidade dentro da escola e a escola dentro da universidade." (UDESC, 2019, p. 20). Assim, o entrosamento construído com as preceptoras em torno dos encaminhamentos, avaliações, impasses e problemas, mobilizava experiências distintas, mas complementares, que foi sendo aprimorado à medida que o programa se desenvolvia.

É importante mencionar ainda que esse trabalho realizado no âmbito do PRP não é díspar nem se trata de uma novidade no programa de estágios do curso de Pedagogia da IES, tanto que as orientações, roteiros, avaliações, premissas quanto ao processo de organização dos projetos de docência, entre outros aspectos, são oriundos de nossa trajetória profissional, com significativo tempo dedicado à formação de professores. No nosso entendimento, o programa, por meio dos convênios firmados entre as IES e a Educação Básica e das bolsas concedidas, incentivam e permitem maior dedicação de todos os envolvidos no processo, resultando, assim, em dois dos principais fatores que têm conferido êxito à proposta: tempo alargado no ambiente escolar e participação das professoras preceptoras.

Podemos destacar, ademais, alguns indicativos que reforçam a necessidade de uma maior atenção para os seguintes aspectos: a forma de inserção dos licenciandos nas escolas; as relações construídas entre as agências formadoras e a Educação Básica; os currículos de licenciatura em vigência. E, de acordo com Nóvoa (2017, p. 18): "O espaço universitário é decisivo e insubstituível, mas tem de se completar com o trabalho no seio de comunidades profissionais docentes."

\section{O Programa de Residência Pedagógica do curso de Geografia}

O PRP do curso de Licenciatura em Geografia teve início no ano de 2018 e sua implantação contou com algumas etapas e fases de organização. Inicialmente, participamos da organização do projeto institucional e elaboração da proposta do subprojeto da área da Geografia em sintonia com a proposta do projeto institucional. Na sequência, foi organizada a formação da equipe que contou com 24 bolsistas, distribuídos/as em três escolas públicas parceiras, localizadas no município de Florianópolis (SC).

O subprojeto da residência em Geografia teve sua organização pautada nos seguintes objetivos: construir espaços de estudo e análise sobre os elementos constitutivos da teoria e da prática do ensino de Geografia; possibilitar a inserção das/os licenciandas/os em Geografia no cotidiano escolar de modo a contribuir para o seu conhecimento sobre a realidade presente na escola; debater com os estudantes as diversas funções atribuídas à Geografia na Educação Básica e seu papel na formação dos sujeitos autônomos e críticos; proporcionar aos acadêmicos/as reflexões acerca da função social da Geografia e do professor de Geografia na sociedade contemporânea para atuar de forma consciente nesse campo do ensino de Geografia; analisar e construir instrumentos metodológicos para o desempenho de uma docência no ensino de Geografia como 
um espaço de reflexão e crítica; produzir diferentes materiais didáticos para os diferentes usos em sala de aula e fora dela, como jogos, mapas, maquetes, histórias em quadrinhos, blogues etc., para o ensino de Geografia na Educação Básica; elaborar textos analíticos sobre a atuação docente no processo de ensino-aprendizagem no ensino de Geografia na Educação Básica.

Todos os movimentos e ações do subprojeto de Geografia foram realizadas no Laboratório de Estudos e Pesquisas de Educação em Geografia (LEPEGEO), onde todas as atividades foram planejadas e organizadas com a participação dos/as acadêmicos/as da graduação em Geografia e os/as acadêmicos/as do Programa de Pós-Graduação em Educação (PPGE/FAED), e serviu de suporte para o planejamento de todas as ações realizadas.

As primeiras atividades realizadas com os/as bolsistas e os/as professores/as preceptores/as foram: organização da formação inicial com orientações sobre a proposta e etapas do edital da residência; planejamento da inserção dos/as bolsistas nas escolas; proposição de leituras da área do ensino de Geografia, formação docente, práticas pedagógicas e currículo. Entendemos que a Residência Pedagógica também é um espaço que oportuniza a reflexão sobre a relação teoria-prática e possibilita qualificar a formação dos futuros/as professores/as. De acordo com Guedes (2018, p. 85-86):

\begin{abstract}
A busca por reconhecer as teorias e, portanto, as concepções que fundamentam o seu trabalho, propicia ao professor uma inscrição, um posicionamento diante dos distintos posicionamentos colocados em disputa pelas construções teóricas de cada autor que pensa a educação. Assim, podemos entender que aliar a reflexão sobre os saberes produzidos nas práticas à reflexão sobre as teorias subjacentes às práticas é um caminho importante para a construção de escolhas mais conscientes sobre a ação docente, construção esta que, a nosso ver, é papel importante da formação.
\end{abstract}

Após essas primeiras etapas, partimos para o planejamento das atividades que seriam realizadas nas três escolas públicas. Os/as bolsistas foram orientados/as para o uso do diário de campo utilizados por todos/ as para anotações de tudo que era realizado no percurso da residência. Essas anotações constituíam-se em relatos das experiências com descrições pessoais que posteriormente seriam organizadas em narrativas para compor as memórias dos relatórios e dos artigos escritos sobre o percurso realizado na residência.

Em cada uma das escolas foram alocados oito bolsistas que, inicialmente, fizeram o reconhecimento do ambiente escolar, investigação das práticas de ensino-aprendizagem, mapeamento dos temas de Geografia e acompanhamento do trabalho do/a professor/a na escola na sua lida com as aulas de Geografia, além de monitoria para auxiliar nas atividades do dia a dia em sala. Após essa primeira fase de inserção na escola, partimos para fase de organização das oficinas de intervenção que seriam realizadas em cada turma.

A organização das oficinas e/ou sequências didáticas com conteúdo e conceitos de Geografia mobilizou experimentações que foram planejadas em conjunto com os/as professores/as preceptores/as em articulação com o Projeto Político-Pedagógico (PPP) da escola e o planejamento da disciplina de Geografia de cada turma. Cada bolsista organizava uma proposta de intervenção e aplicava em uma ou mais turmas, conforme planejado com o/a preceptor/a. Todo esse processo movimentou o planejamento das atividades que eram realizadas nas escolas e contou com o auxílio e a supervisão da coordenação do Projeto de Residência em Geografia.

A realização das oficinas e sequências didáticas como possibilidade de trabalhar em sala de aula, entre outras opções metodológicas, possibilitaram que os/as estudantes trabalhassem com produções individuais e 
coletivas, com trabalhos em grupo, permitindo um maior envolvimento com as ações propostas nas aulas de Geografia. Acreditamos que um bom planejamento das oficinas e atividades de intervenção em sala de aula auxiliariam para dar segurança na condução do processo com os/as estudantes. Segundo Oliveira (2007, p. 21),

o ato de planejar exige aspectos básicos a serem considerados. Um primeiro aspecto é o conhecimento da realidade daquilo que se deseja planejar, quais as principais necessidades que precisam ser trabalhadas; para que o planejador as evidencie faz-se necessário fazer primeiro um trabalho de sondagem da realidade daquilo que ele pretende planejar, para assim, traçar finalidades, metas ou objetivos daquilo que está mais urgente de se trabalhar.

Para efetivar o acompanhamento das atividades foram realizados, periodicamente, encontros para socialização das práticas e narrativas individuais e coletivas das ações realizadas nas escolas, considerados momentos ricos para troca de saberes e para a escuta dos/as colegas sobre as vivências próprias do terreno das práticas na escola. Além disso, foram feitas exposições de trabalhos construídos a partir das oficinas e sequências didáticas em eventos realizados na Universidade, e organizados dois seminários em conjunto com o subprojeto de residência da Pedagogia com a finalidade de promover trocas sobre as experiências e atividades desenvolvidas. Todas essas ações tiveram como objetivo contribuir para o aprimoramento da formação e a articulação entre o que os/as residentes aprendem na Universidade e o que experimentam na prática da residência.

O PRP, que tem na sua gênese o objetivo de qualificar e fortalecer a formação dos discentes de cursos de licenciatura, por meio do desenvolvimento de projetos que fortaleçam o campo da prática, consolidando a relação entre a universidade e as unidades escolares, propõe uma vivência e imersão nas escolas para exercitar de forma ativa a relação teoria e prática profissional. Nesse sentido, no subprojeto Geografia, sempre tivemos a preocupação de acompanhar as atividades dos/as residentes/as nos planejamentos e nas escolas em conjunto com os/as preceptores/as para auxiliar nas dificuldades encontradas no cotidiano da sala de aula, desenvolvendo um trabalho colaborativo para que pudessem enfrentar os desafios na busca de criar outras geografias possíveis e assim movimentar o pensamento dos/as estudantes da Educação Básica.

\section{Considerações finais}

O trabalho se dispôs a problematizar e analisar as experiências do Programa de Residência Pedagógica (PRP) realizado nas licenciaturas em Pedagogia e em Geografia de uma universidade pública estadual. O detalhamento das ações planejadas, realizadas e sistematizadas, evidenciaram a inserção contínua e ampliada dos/ as licenciandos/as nos espaços da escola, estimulando o protagonismo das redes de ensino, em especial das professoras preceptoras. Também foi possível identificar o aperfeiçoamento da formação dos/as estudantes e a acentuação da relação teoria e prática numa perspectiva crítica, orientada e participativa.

Houve ainda a promoção de momentos e espaços de discussão sobre a dinâmica dos currículos de formação inicial de professores para a Educação Básica e sua relação com as orientações da BNCC de forma crítica e prospectiva, o que contribuiu para o aperfeiçoamento do estágio curricular ao oportunizar uma maior inserção dos/as residentes no espaço escolar. Essa inserção possibilitou uma visão amplificada da escola e da profissão docente, e a presença contínua e sistemática na escola oportunizou o desenvolvimento de atividades, vivências e a proximidade ao exercício da profissão docente, envolvendo, além dos aspectos didáticos, como planejamento, ação docente, orientação e acompanhamento da aprendizagem dos estudantes, a relação com a comunidade escolar, a participação em reuniões pedagógicas, conselhos de classe, entre outras atividades pertinentes. As avaliações aplicadas demonstraram o reconhecimento por parte dos/as residentes e dos/as preceptores/as da efetiva contribuição do PRP na formação de ambos. 
A ênfase do Programa à dimensão da prática não significou a redução dos aportes teóricos dos cursos de graduação, ao contrário, demonstrou o quanto é necessário que as áreas dos Fundamentos da Educação componham os currículos de licenciatura, uma vez que qualificam e fundamentam as ações docentes em todas as dimensões e etapas. Entendemos que protagonismo e autonomia somente podem ocorrer acompanhados de constantes reflexões, efetiva participação e fundamentação teórico-metodológica.

A construção de uma parceria com as redes de ensino, escolas e professores/as preceptores/as propiciou: a) desenvolvimento de uma perspectiva colaborativa de formação, o que implica numa proposta de estágio mais articulada com as demandas da Educação Básica; b) revisão da forma de organização dos estágios, em especial quanto à relação com o/a docente preceptor/a que passa a ter um papel mais ativo e participativo na formação dos/as licenciandos/as, valorizando assim os conhecimentos advindos da prática docente de um profissional mais experiente; c) tempo mais alongado e contínuo de inserção na cultura escolar, nesse caso, nos anos iniciais, o que proporciona uma maior compreensão dos processos de ensino e aprendizagem, dos processos de gestão, da relação com o contexto escolar, com as famílias e com a comunidade; d) superação da perspectiva de campo de estágio como mero receptor de estagiários/as.

Também foi perceptível o significativo aumento das produções e discussões no âmbito acadêmico e científico sobre o processo de formação inicial e o PRP, o que esperamos resultar em ações políticas e institucionais mais articuladas e que valorizem a carreira docente. À guisa de exemplo, podemos citar o evento acadêmico conjunto XII Seminário Nacional de Formação dos Profissionais da Educação / 40 Encontro Nacional do FORUMDIR / I Seminário Nacional do FORPARFOR e FORPIBID RP, realizado em Salvador (BA), em setembro de 2019, na Faculdade de Educação da Universidade Federal da Bahia (FACED/UFBA), cujo tema central foi "Formação de Professores: políticas, projetos, desafios e perspectivas de resistência".

Podemos afirmar que a experiência com o PRP propiciou com maior vigor o fortalecimento da relação Universidade e Educação Básica através das parcerias já realizadas e, em especial, nos momentos de socialização e exposição das atividades do PRP quando havia maior evidência e participação dos/as representantes das esferas envolvidas, ressaltando a importância e a necessidade de políticas dessa natureza, demonstrando, assim, considerável convergência em torno de uma formação docente mais articulada e colaborativa entre as IES e os sistemas de ensino.

O incentivo por meio de bolsas para a iniciação à docência, como o PRP, pode ser considerado tardio, em relação aos demais programas, como os de pesquisa e extensão, uma vez que a articulação entre ensino, pesquisa e extensão, ao menos nas universidades, é uma exigência legal. Assim, é necessário pensar na ampliação e manutenção do Programa como uma política contínua, sem as rupturas e inseguranças sob as quais é submetido de tempos em tempos.

É necessário destacar que programas e experiências da natureza do PRP, e mesmo do PIBID, embora venham demonstrando êxito e relevância, não garantem os grandes objetivos que acompanham os respectivos editais e portarias se não forem criadas e mantidas políticas específicas para tal, e, em conjunto com uma série de medidas, como o reconhecimento e a valorização da carreira docente, a prática de criação de políticas educacionais mais participativas, maior investimento no setor da educação pública e o reconhecimento do cotidiano da escola como um lugar de elaboração de conhecimento, possibilitando ao professor da Educação Básica condições concretas para refletir criticamente, problematizar e pesquisar sobre sua prática, ampliando e fortalecendo assim as conexões entre as IES e as escolas básicas, no âmbito da pesquisa, do ensino e da extensão. 


\section{REFERÊNCIAS}

BRASIL, Ministério da Educação. Planejando a próxima década: conhecendo as 20 metas do Plano Nacional de Educação. Brasília: Ministério da Educação, Secretaria de Articulação com os Sistemas de Ensino (MEC/ SASE), 2014. Disponível em: <http://pne.mec.gov.br/images/pdf/pne_conhecendo_20_metas.pdf>. Acesso em: 21 set. 2020.

COORDENAÇÃO DE APERFEIÇOAMENTO DE PESSOAL DE NIVEL SUPERIOR (CAPES). Edital CAPES $n^{\circ}$ 06/2018. Programa de Residência Pedagógica. Chamada Pública para apresentação de propostas no âmbito do Programa de Residência Pedagógica. Brasília, $1^{\circ}$ mar. 2018. Disponível em: <https://www.capes.gov.br/images/stories/download/editais/01032018-Edital-6-2018-Residencia-pedagogica.pdf>. Acesso em: 21 set. 2020.

DESGAGNÉ, Serge. O conceito de pesquisa colaborativa: a ideia de uma aproximação entre pesquisadores universitários e professores práticos. In Revista Educação em Questão, Natal, v. 29, n. 15, p. 7-35, maio/ ago. 2007.

FRANCO, Maria Amélia Santoro. Pedagogia da pesquisa-ação. In Educação e Pesquisa, São Paulo, v. 31 , n. 3, p. 483-502, set./dez. 2005.

GUEDES; Luísa Azevedo. O Programa de Residência Docente do Colégio Pedro II: escritas de formação na área dos Anos Iniciais do Ensino Fundamental. 2018. 162f. Tese (Doutorado em Educação) Universidade Federal do Rio de Janeiro - Rio de Janeiro, 2018. Disponível em: <https://ppge.educacao.ufrj.br/teses2018/ tLuizaGuedes.pdf>. Acesso em: 21 set. 2020.

LÜDKE, Menga; CRUZ, Giseli Barreto da. Aproximando universidade e escola de educação básica pela pesquisa. In Cadernos de Pesquisa, v. 35, n. 125, p. 81-109, maio/ago. 2005. Disponível em: <https://www. scielo.br/pdf/cp/v35n125/a0635125.pdf>. Acesso em: 21 set. 2020.

MARTINS FILHO, Altino José; MARTINS FILHO, Lourival José. Docência: protagonismo compartilhado. In Presença Pedagógica, v. 18, p. 44-49, 2012.

NÓVOA, António. Firmar a profissão como professor, afirmar a profissão docente. In Cadernos de Pesquisa, v. 47, n. 166, p. 1.106-1.133, out./dez. 2017. Disponível em: https://www.scielo.br/pdf/cp/v47n166/1980-5314cp-47-166-1106.pdf. Acesso em 10 de julho de 2020.

NÓVOA, António. Para uma formação de professores construída dentro da profissão. In: Revista de Educación, n. 350, sept./dic. 2009, p. 203-218. Disponível em: <http://www.revistaeducacion.educacion.es/re350/ re350_09por.pdf>. Acesso em: 21 set. 2020.

NÓVOA, António. Os professores e sua formação num tempo de metamorfose da escola. In: Educação \& Realidade, Porto Alegre, v. 44, n. 3, e84910, 2019. Disponível em: https://www.scielo.br/pdf/edreal/v44n3/21756236-edreal-44-03-e84910.pdf. Acesso em: 18 de agosto de 2020.

OLIVEIRA, Dalila de Andrade. Gestão democrática da educação: desafios contemporâneos. 7. ed. Petrópolis: Vozes, 2007. 
TARDIF, Maurice. Saberes docentes e formação profissional. Petrópolis: Vozes, 2002.

THIOLLENT, Michel. Metodologia da pesquisa-ação. São Paulo: Cortez Editora, 2005.

TRIPP, David. Pesquisa-ação: uma introdução metodológica. In Educação e Pesquisa, São Paulo, v. 31, n. 3 , p. 443-466, set./dez. 2005.

UNIVERSIDADE DO ESTADO DE SANTA CATARINA (UDESC). Projeto Institucional do Programa de Residência Pedagógica de Pedagogia (PRP/Pedagogia). Universidade do Estado de Santa Catarina (UDESC), Florianópolis, 2018.

UNIVERSIDADE DO ESTADO DE SANTA CATARINA (UDESC). Relatório final do Programa de Residência Pedagógica de Pedagogia (PRP/Pedagogia). Universidade do Estado de Santa Catarina (UDESC). Florianópolis, 2019.

VYGOTSKY, Lev. S. Pensamento e linguagem. São Paulo: Martins Fontes, 1982.

SOUZA, A. R. B.; MARTINS FILHO, L. J.; MARTINS, R. E. M. W.; Programa de residência pedagógica: conexões entre a formação docente e a educação básica Formação Docente - Revista Brasileira de Pesquisa sobre Formação de Professores. Belo Horizonte. Vol. 13, n. 25 (p. 137-150) 31 dez. 2020. ISSN:2176-4360. DOI https://doi. org/10.31639/rbpfp.v13i25.410 
